\title{
PENGARUH FASILITAS DAN KUALITAS PELAYANAN TERHADAP KEPUTUSAN MENGGUNAKAN JASA TRANSPORTASI MRT ATAU MASS RAPID TRANSIT (STUDI PADA KONSUMEN PROVINSI DKI JAKARTA)
}

\author{
${ }^{1}$ Aris Fatoni ${ }^{2}$ Deffi Hardianti \\ Email: ${ }^{1}$ tony_fatt@yahoo.com ${ }^{2}$ deffihardianti@gmail.com \\ ${ }^{1}$ Program Studi Administrasi Bisnis, Fakultas IImu Sosial \& IImu Politik \\ ${ }^{2}$ Mahsiswa Program Studi Administrasi Bisnis, Fakultas IImu Sosial \& IImu Politik \\ Institut Bisnis Dan Informatika Kosgoro 1957
}

\begin{abstract}
ABSTRAK
Pendahuluan: Moda transportasi MRT merupakan moda transportasi baru di Jakarta. Moda transportasi kereta ini menawarkan kecepatan pelayanan dan kemodernan berbagai fasilitas serta menjadi salah satu solusi untuk mengatasi kemacetan di kota Jakarta. Hal ini tentu sangat menarik bagi masyarakat untuk menggunakan jasa transportasi tersebut. Tujuan: tujuan penelitian ini untuk mengetahui pengaruh fasilitas dan kualitas pelayanan terhadap keputusan penggunaan jasa transportasi MRT Jakarta. Metode: penelitian ini menggunakan pendekatan kuantitatif dengan metode survei. Sampel berjumlah 100 responden, ditarik dari pelanggan kereta MRT Jakarta dengan menggunakan teknik simple random sampling. Hasil penelitian: hasil penelitian ini menunjukkan bahwa fasilitas dan kualitas pelayanan baik secara parsial maupun simultan berpengaruh secara signifikan terhadap keputusan penggunaan jasa transportasi kereta MRT Jakarta. Kontribusi keberpengaruhan fasilitas dan kualitas pelayanan terhadap keputusan penggunaan jasa transportasi kereta MRT Jakarta sebesar $86,1 \%$.

Kata Kunci: Fasilitas, Kualitas Pelayanan, Keputusan Menggunakan Jasa, Transportasi
\end{abstract}

\section{ABSTRACT}

Introduction: MRT mode of transportation is a new mode of transportation in Jakarta. This train transportation mode offers speed of service and modernity of various facilities and is one of the solutions to overcome traffic congestion in the city of Jakarta. This is certainly very interesting for the public to use the transportation service. Purpose: the purpose of this study was to determine the effect of facility and service quality on the decision to use Jakarta MRT transportation services. Method: this research uses a quantitative approach with a survey method. A sample of 100 respondents was drawn from Jakarta MRT train customers using simple random sampling technique. Research results: the results of this study indicate that the facilities and service quality both partially and simultaneously significantly influence the decision to use the Jakarta MRT train transportation services. The contribution of influencing facilities and service quality to the decision to use the Jakarta MRT train transportation services was $86.1 \%$

Keywords: Facilities, Service Quality, Decision to Use Services, Transportation 


\section{PENDAHULUAN}

\section{I.1. Latar Belakang}

Transportasi merupakan sarana yang sangat penting dan strategis dalam memperlancar roda perekonomian, menghubungkan antar satu wilayah ke wilayah lain yang mempengaruhi berbagai aspek kehidupan. Perpindahan tempat dilakukan manusia dengan menggunakan berbagai moda transportasi seperti sepeda, kereta, bus, becak, bemo, motor, mobil, bajaj ataupun dengan berjalan kaki. Dengan berbagai macam pilihan, masyarakat bebas memilih moda transportasi sesuai keinginan mereka, namun permasalahan kemacetan lalu lintas sulit dihindarkan dalam transportasi kota.

Jakarta adalah ibu kota Indonesia, pada akhir tahun 2019 jumlah penduduk ibu kota sebanyak 11.063.324 jiwa (statistic.jakarta.go.id). Diperkirakan bahwa lebih dari 4,5 (empat) juta penduduk di daerah sekitar Jabodetabek menempuh perjalanan ke dan dari kota setiap hari kerja. Berdasarkan hasil survei yang dirilis Tom-Tom Index, pada tahun 2017,Jakarta merupakan kota termacet ke-4 di dunia, lalu setahun kemudian menjadi nomor 7, dan tahun 2019, Jakarta menempati posisi kota termacet di dunia pada urutan ke-10.

Kurangnya daya tampung jalan membuat pergerakan kendaraan tidak dapat berjalan normal. Menurut Pemerhati Masalah Transportasi, Budiyanto, dari tahun 2015-2019 pertumbuhan kendaraan bermotor di Jadetabek sebesar $9,3 \%$ sedangkan pertumbuhan pembangunan infrastruktur hanya sebesar $0,1 \%$ (gridoto.com). Hasil Study on Integrated Transportation Master Plan (SITRAMP) oleh JICA/Bappenas menunjukkan, bahwa jika sampai tahun 2020 tidak ada perbaikan yang dilakukan pada sistem transportasi di Jakarta, maka estimasi kerugian ekonomi yang terjadi sebesar Rp. 100 Triliun (detik.com).

Berbagai program pengendalian kemacetan seperti pengadaan Bus Transjakarta dan APTB, pelarangan sepeda motor di jalan tertentu, pemberlakuan three in one, juga penjadwalan ganjil genap bagi kendaraan 
roda empat terlihat belum membuahkan hasil. (lib.ui.ac.id). Pilihan pembangunan moda transportasi Mass Rapid Transit (MRT) pun menjadi sangat ditunggu masyarakat DKI Jakarta dalam upaya mengatasi kemacetan. MRT Jakarta atau singkatan dari Mass Rapid Transit Jakarta, merupakan moda transportasi raya terpadu atau angkutan cepat terpadu Jakarta adalah sebuah sistem transportasi transit cepat menggunakan kereta rel listrik yang sudah dibangun di Jakarta.

Berbagai fasilitas di stasiun MRT disediakan untuk mempermudah pelayanan konsumen. Untuk masuk ke dalam stasiun, baik layang maupun bawah tanah, disediakan fasilitas eskalator, elevator, dan tangga. Sebuah area concourse juga tersedia. Di dalam stasiun, terdapat fasilitas ruang pertolongan pertama, toilet umum, Platform Screen Door (PSD), tempat duduk, station front office untuk layanan penumpang (customer services), ticket sales office (TOM), public announcement, serta tactile untuk penyandang disabilitas, dll.

Layanan yang ditawarkan MRP diantaranya berupa kenyamanan, keamanan dalam perjalanan, kepastian jadwal perjalanan, ketepatan waktu sampai tujuan dll. Untuk kereta bawah tanah, sinyal telekomunikasi tetap bisa diakses oleh penumpang meskipun berada di dalam terowongan hingga kedalaman mencapai 20 meter.

\section{I.2. Tujuan Penelitian}

Tujuan Penelitian ini adalah untuk mengetahui:

1. Pengaruh fasilitas terhadap keputusan penggunaan jasa transportasi Mass Rapid Transit (Studi pada Konsumen Provinsi DKI Jakarta)

2. Pengaruh kualitas pelayanan terhadap keputusan penggunaan jasa transportasi Mass Rapid Transit (Studi pada Konsumen Provinsi DKI Jakarta)

3. Pengaruh fasilitas dan kualitas pelayanan terhadap penggunaan jasa transportasi Mass Rapid Transit (Studi pada Konsumen Provinsi DKI Jakarta) 


\section{I.3. Fasilitas dan Keputusan Penggunaan Jasa}

Fasilitas menjadi salah satu pertimbangan dalam menentukan pilihan jasa transportasi. Semakin lengkap fasilitas yang diberikan, semakin memudahkan konsumen untuk menikmati jasa yang berikan sekaligus menjadi pembeda dengan perusahaan lain. Hal ini kemudian menjadi dasar penilaian konsumen atas kinerja jasa. Sejalan dengan penemuan Lempoy, Mandey dan Loindong (2015) bahwa fasilitas memiliki pengaruh terhadap keputusan menggunakan jasa, namun berbanding terbalik dengan penemuan Desembrianita (2016) yang menunjukkan bahwa secara parsial fasilitas tidak berpengaruh terhadap keputusan pelanggan dalam menggunakan jasa. Untuk itu peneliti ingin membuktikan apakah dalam penelitian ini, fasilitas menjadi salah satu elemen yang mempengaruhi pelanggan MRT Jakarta menggunakan moda transportasi tersebut atau tidak. Berdasarkan uraian tersebut, hipotesis yang diajukan dalam penelitian ini adalah sebagai berikut:

$\mathrm{H}_{0}=\quad$ Tidak terdapat pengaruh secara signifikan antara fasilitas terhadap keputusan penggunaan jasa.

$\mathrm{H}_{1}=\quad$ Terdapat pengaruh secara signifikan antara fasilitas terhadap keputusan penggunaan jasa.

\section{I.4. Kualitas Pelayanan dan Keputusan Penggunaan Jasa}

Selain fasilitas, pertimbangan lain dalam menentukan pilihan jasa transportasi yaitu kualitas pelayanan. Kualitas pelayanan yang tinggi menjadi keunggulan bersaing bagi perusahaan jasa. Suatu pelayanan dapat dikatakan berkualitas apabila pelayanan tersebut memenuhi atau melebihi ekspektasi (harapan) konsumen. Ikatan atau hubungan yang kuat akan terjalin dengan baik antara perusahaan dengan konsumen, jika pelayanan yang diberikan berkualitas. Dalam jangka panjang ikatan yang kuat ini membantu perusahaan dalam memahami harapan dan kebutuhan konsumen secara terus menerus. Dalam hal ini, apabila perusahaan jasa transportasi MRT mampu memberikan pelayanan sesuai dengan harapan 
dan kebutuhan konsumen, maka konsumen juga dapat mempertimbangkan sebagai faktor dalam memilih jasa transportasi MRT. Hal ini sejalan dengan penemuan Trisnowati dan Nugraha (2016) bahwa kualitas pelayanan mempunyai pengaruh yang positif dan signifikan terhadap keputusan penggunaan jasa. Berdasarkan uraian tersebut, hipotesis yang diajukan dalam penelitian ini adalah sebagai berikut:

$\mathrm{H}_{0}=\quad$ Tidak terdapat pengaruh secara signifikan antara kualitas pelayanan terhadap keputusan penggunaan jasa

$\mathrm{H}_{1}=\quad$ Terdapat pengaruh secara signifikan antara kualitas pelayanan terhadap keputusan penggunaan jasa

\section{I.5. Fasilitas, Kualitas Pelayanan dan Keputusan Penggunaan Jasa}

Fasilitas dan kualitas pelayanan yang baik akan mendorong pelanggan menggunakan suatu jasa tertentu. Fasilitas akan mempermudah pelanggan menggunakan jasa yang ditawarkan, kualitas pelayanan akan menghasilkan kepuasan pelanggan, sehingga berpengaruh pada keputusan untuk menggunakan jasa. Hal ini sejalan dengan penemuan Permasari dan Hadi (2017) bahwa fasilitas dan kualitas pelayanan berpengaruh secara signifikan terhadap keputusan menggunakan jasa. Berdasarkan uraian tersebut, hipotesis yang diajukan dalam penelitian ini adalah sebagai berikut:

$\mathrm{H}_{0}=\quad$ Tidak terdapat pengaruh secara signifikan antara fasilitas dan kualitas pelayanan terhadap keputusan penggunaan jasa

$\mathrm{H}_{1}=\quad$ Terdapat pengaruh secara signifikan antara fasilitas dan kualitas pelayanan terhadap keputusan penggunaan jasa 


\section{I.6. Kerangka Pemikiran}

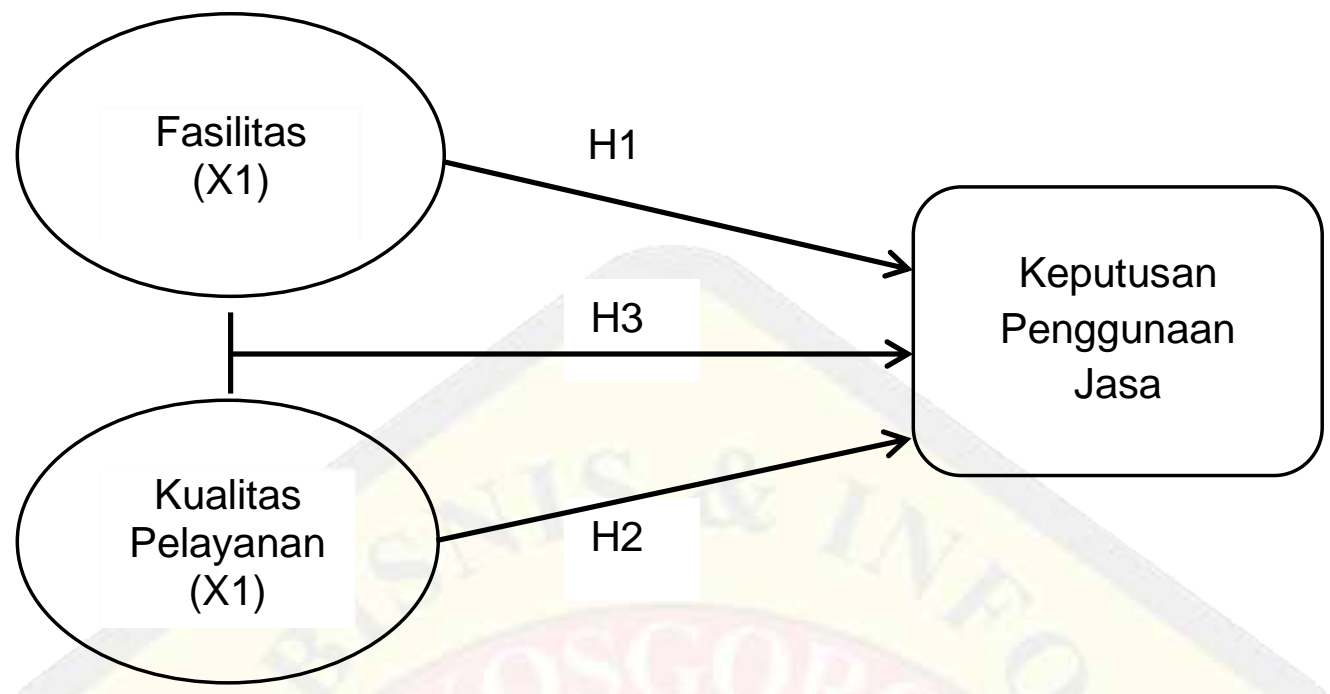

\section{KAJIAN PUSTAKA}

\section{II.1. Fasilitas}

Menurut Tjiptono (2014:317) fasilitas merupakan sumber daya fisik yang harus ada sebelum suatu jasa ditawarkan kepada konsumen. Fasilitas meliputi kondisi fasilitas, desain interior dan eksterior.

Menurut Tjiptono (2014:318) ada beberapa unsur-unsur yang perlu dipertimbangkan dalam menentukan fasilitas jasa diantaranya adalah perencanaan spasial, perencanaan ruangan, perlengkapan, tata cahaya, warna, pesan-pesan yang disampaikan secara grafis, dan unsur pendukung.

\section{II.2. Kualitas Pelayanan}

Menurut Wyock dalam lovelock, 1988 yang dikutip oleh Fandy Tjiptono (2014:268) "Kualitas pelayanan merupakan tingkat keunggulan (excellent) yang diharapkan dan pengendalian atas keunggulan tersebut untuk memenuhi kebutuhan konsumen".

Menurut Kotler dan Amstrong (2012: 284) menyebutkan lima dimensi kualitas pelayanan jasa yang harus dipenuhi, yaitu bukti fisik (tangible), 
keandalan (reliability), daya tanggap (responsiveness), jaminan (assurance), empati (empathy).

\section{II.3. Keputusan Pembelian}

Menurut Kotler dan Amstrong (2012:166) menyebutkan Keputusan pembelian merupakan tahapan dimana konsumen membentuk preferensi antar merek dalam kumpulan pilihan. Dalam melakukan keputusan pembelian, konsumen ditentukan melalui lima sub keputusan yaitu merek, penjual, kuantitas, waktu dan juga bagaimana metode pembelian yang akan dilakukan.

Untuk mengukur keputusan pembelian yang diambil oleh konsumen terdapat tiga dimensi antara lain Sutisna \& Pawitra (2001:59); asosiasi manfaat, frekuensi pembelian, prioritas dalam membeli.

\section{METODE PENELITIAN}

Pendekatan dalam penelitian ini menggunakan pendekatan kuantitatif dengan metode survei. Populasinya adalah Konsumen jasa transportasi Mass Rapid Transit di provinsi DKI Jakarta. Sampel berjumlah 100 responden ditarik dengan menggunakan teknik simple random sampling. Alat analisis dalam penelitian ini menggunakan analisis regresi linear berganda, pengujian hipotesis $\mathrm{F}$ dan uji hipotesis t. Untuk analisis deskripsi menggunakan nilai indeks untuk mendapatkan gambaran mengenai derajat penilaian responden atas variabel yang diteliti (Ferdinand, 2014:232).

\section{III.1. Definisi Operasional}

Variabel bebas dalam penelitian ini adalah fasilitas dan kualitas pelayanan. Fasilitas didefinisikan penyediaan sarana dan prasarana fisik kepada para pelanggan untuk mempermudah dalam melaksanakan berbagai aktivitas yang disediakan guna menunjang dan memenuhi kebutuhan pelanggan meliputi; pertimbangan spasial, perencanaan 
ruangan, perlengkapan, tata cahaya, warna, pesan-pesan yang disampaikan secara grafis dan unsur pendukung.

Kualitas pelayanan didefinisikan sebagai tingkat keunggulan pelayanan yang diharapkan dapat dinikmati oleh pelanggan dan secara kontinu keunggulan tersebut dapat dipertahankan dan ditingkatkan yang meliputi beberapa elemen, yaitu bukti fisik (tangible), keandalan (reliability), daya tanggap (responsiveness), jaminan (assurance), empati (empathy).

Variabel bebas dalam penelitian ini adalah keputusan pembelian. Keputusan pembelian merupakan tahap dalam proses pengambilan keputusan pembelian, yaitu proses berpikir yang dilalui konsumen yang menghasilkan berbagai bentuk atau kumpulan pilihan suatu produk, kemudian menjatuhkan pilihan terhadap produk yang disukai, kemudian memutuskan untuk membeli produk dengan beberapa pertimbangan. Keputusan pembelian diukur dengan beberapa elemen, yaitu asosiasi manfaat, frekuensi pembelian, prioritas dalam membeli.

\section{III.2. Teknik pengumpulan Data}

Pengumpulan data dilakukan dengan menggunakan kuesioner. Kuesioner dibangun berdasarkan indikator-indikator dengan alat ukur semantic differensial dengan skala 1 sampai 7.

\section{Tabel 1. Operasionalisasi Variabel Penelitian}

\begin{tabular}{|c|c|c|}
\hline VARIABEL & DIMENSI & INDIKATOR \\
\hline \multirow[t]{2}{*}{ Fasilitas } & Pertimbangan Spasial & $\begin{array}{l}\text { Layout stasiun yang menarik (X1.1) } \\
\text { Area stasiun manampilkan kesan modern (X1.2) }\end{array}$ \\
\hline & Perencanaan Ruangan & $\begin{array}{l}\text { Gerbong kereta yang baru dan elegan (X1.3) } \\
\text { Kursi penumpang (X1.4) } \\
\text { Eskalator (X1.5) } \\
\text { Elevator (khusus penyandang disabilitas, orang tua dan } \\
\text { ibu hamil) (X1.6) } \\
\text { Pendingin ruangan (X1.7) } \\
\text { Gerai komersial (X1.8) } \\
\text { Station front office (X1.9) } \\
\text { Ticket sales office (TOM) (X1.10) } \\
\text { Tactile untuk penyandang disabilitas (X1.11) } \\
\text { Passenger information display (X1.12) } \\
\text { Bangku prioritas (Priority seat) }(\mathrm{X} 1.13) \\
\text { Bagasi barang (X1.14) } \\
\text { Ruang pertolongan pertama (X1.15) }\end{array}$ \\
\hline
\end{tabular}




\begin{tabular}{|c|c|c|}
\hline & & Platform Screen Door (PSD) (X1. 16) \\
\hline & Perlengkapan & $\begin{array}{l}\text { Ticket Vending Machine (TVM) (X1.17) } \\
\text { Top up Machine (AVM) (X1.18) }\end{array}$ \\
\hline & Tata Cahaya & Pencahayaan yang cukup (X1.19) \\
\hline & Warna & Desain warna gerbong yang bagus $(\mathrm{X} 1.20)$ \\
\hline & $\begin{array}{l}\text { Pesan - Pesan yang } \\
\text { disampaikan secara grafis }\end{array}$ & $\begin{array}{l}\text { Logo kereta MRT (X1.21) } \\
\text { Public Announcement (X1.22) }\end{array}$ \\
\hline & Unsur Pendukung & Free Hotspot (X1.23) \\
\hline \multirow{5}{*}{$\begin{array}{l}\text { Kualitas } \\
\text { Pelayanan }\end{array}$} & Tangibles (nyata) & Penampilan petugas (X2.1) \\
\hline & Reliability (keandalan) & Dapat diandalkan dalam melayani konsumen (X2.2) \\
\hline & $\begin{array}{l}\text { Responsiveness (daya } \\
\text { tanggap) }\end{array}$ & $\begin{array}{l}\text { Cepat tanggap dalam kesediaan merespon kebutuhan } \\
\text { konsumen (X2.3) }\end{array}$ \\
\hline & Assurance (jaminan) & $\begin{array}{l}\text { Membuat konsumen merasa aman selama perjalanan } \\
(\mathrm{X} 2.4)\end{array}$ \\
\hline & Emphaty (perhatian) & $\begin{array}{l}\text { Memprioritaskan penyandang disabilitas, lansia dan } \\
\text { ibu hamil (X2.5) }\end{array}$ \\
\hline \multirow{3}{*}{$\begin{array}{l}\text { Keputusan } \\
\text { Pembelian }\end{array}$} & Benefit Association & Kemudahan \& kenyamanan bertransportasi (Y1) \\
\hline & Frekuensi Pembelian & Menggunakan jasa terus menerus (Y2) \\
\hline & Prioritas Dalam Membeli & $\begin{array}{l}\text { Merekomendasikan kepada orang lain (Y3) } \\
\text { Pelayanan jasa kereta MRT jauh lebih baik } \\
\text { dibandingkan jasa transportasi lain (Y4) }\end{array}$ \\
\hline
\end{tabular}

\section{HASIL DAN PEMBAHASAN}

\section{IV.1. Profil Responden Berdasarkan Jenis Kelamin}

Profil responden berdasarkan jenis kelamin menunjukkan bahwa konsumen laki-laki lebih banyak menggunakan jasa transportasi kereta MRT Jakarta dengan frekuensi responden laki-laki sebanyak 53 orang atau $53 \%$, dan sisanya sebanyak 47 orang atau $47 \%$ adalah perempuan.

Profil responden berdasarkan jenis kelamin dapat dilihat dalam Gambar 1 berikut ini:

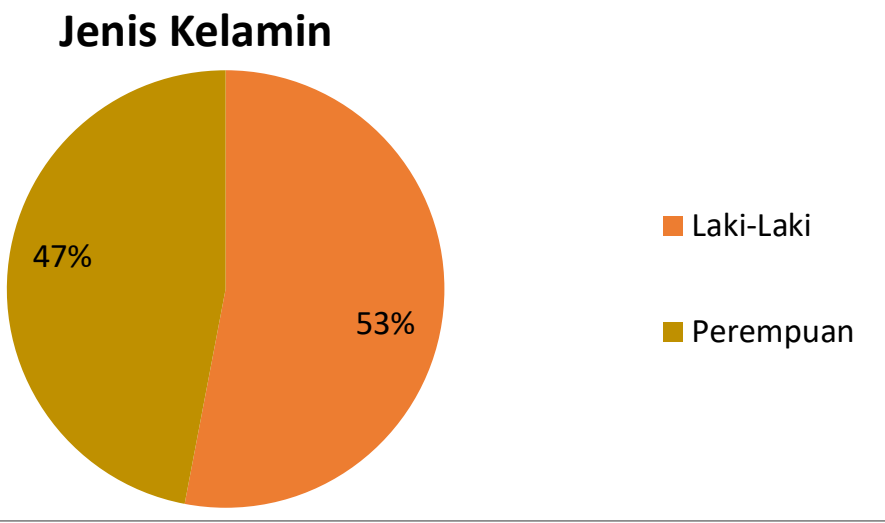

Gambar 1. Diagram Frekuensi Responden Berdasarkan Jenis Kelamin Sumber: Diolah dari data primer 


\section{IV.2. Profil Responden Berdasarkan Usia}

Profil responden berdasarkan Usia menujukan bahwa jumlah responden dengan usia 17-25 tahun berjumlah 47 orang atau $47 \%$, usia 26-35 berjumlah 32 orang atau $32 \%$, usia 36-45 berjumlah 16 orang atau $16 \%$ dan 5 orang tua $5 \%$ responden yang berusia $>45$ tahun.

Profil responden berdasarkan Usia dapat dilihat dalam Gambar 2 berikut ini:

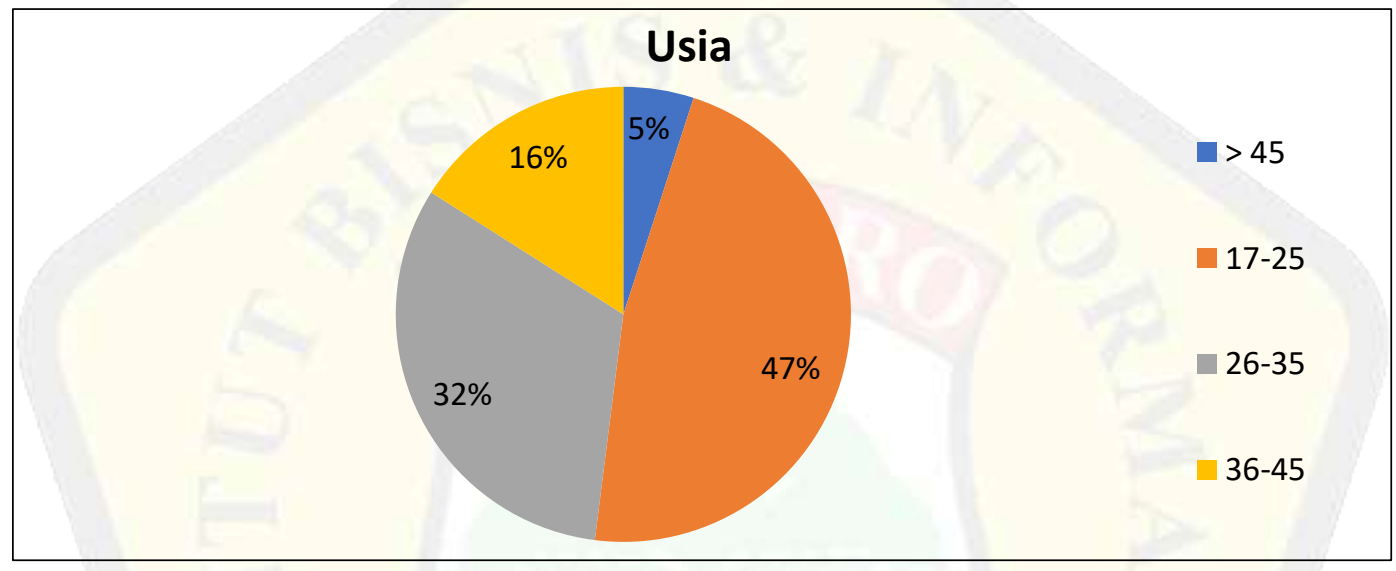

Gambar 2. Diagram Frekuensi Responden Berdasarkan Usia Sumber : Diolah dari data primer

\section{IV.3. Profil Responden berdasarkan Status/Pekerjaan}

Profil responden berdasarkan Status atau pekerjaan menunjukkan bahwa jumlah responden dengan status Pengusaha sebanyak 16 orang atau $16 \%$, ASN (Aparatur Sipil Negara) sebanyak 16 orang atau $16 \%$, Pegawai Swasta 39 orang atau $39 \%$ dan Mahasiswa sebanyak 29 orang atau $29 \%$.

Profil responden berdasarkan Status/Pekerjaan dapat dilihat dalam Gambar 3 berikut ini: 


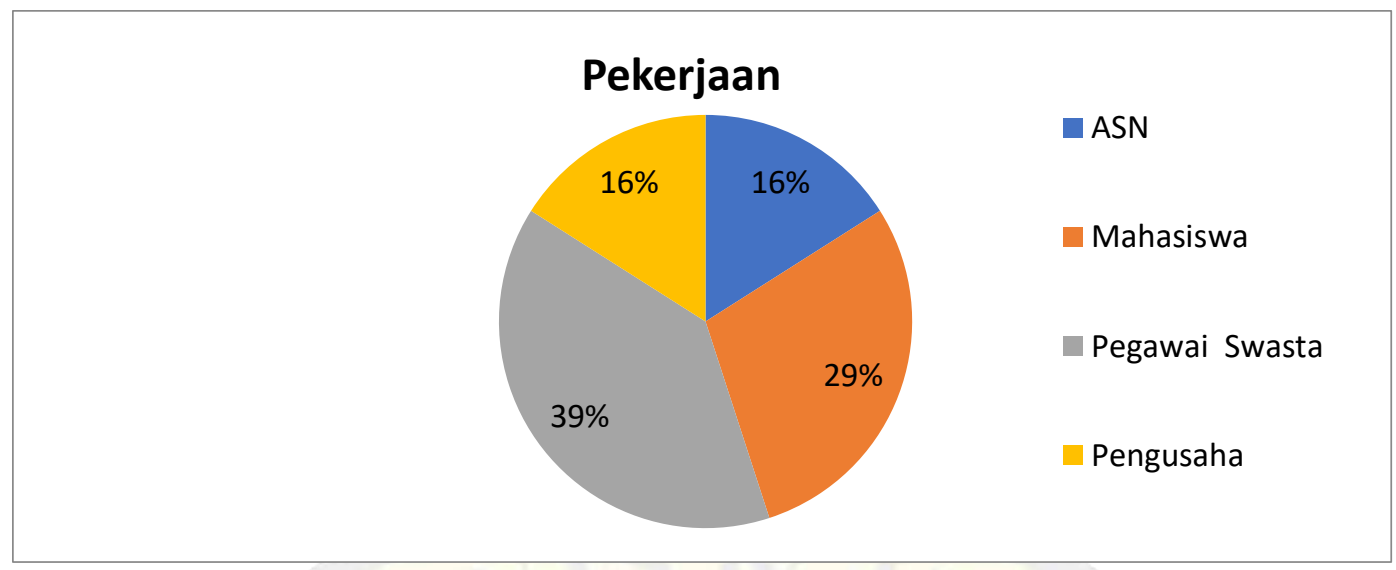

\section{Gambar 3. Diagram Frekuensi Responden Berdasarkan Status/Pekerjaan \\ Sumber: Diolah dari data primer}

\section{IV.4. Frekuensi menggunakan kereta MRT Jakarta}

Profil responden berdasarkan Seberapa sering menggunakan kereta MRT Jakarta menunjukkan bahwa jumlah responden dengan melakukan perjalanan 1-2 kali per minggu sebanyak 31 orang atau $31 \%$, 3-4 kali per minggu sebanyak 39 orang atau $39 \%$, dan $\geq 5$ kali per minggu sebanyak 30 orang atau $30 \%$. Data ini diperoleh berdasarkan penyebaran kuesioner tentang Pengaruh Harga, Fasilitas dan Kualitas Pelayanan Terhadap Keputusan Pemilihan Moda Transportasi Kereta MRT Jakarta.

Profil responden berdasarkan Seberapa sering menggunakan kereta MRT Jakarta dapat dilihat dalam Gambar 4 berikut ini :

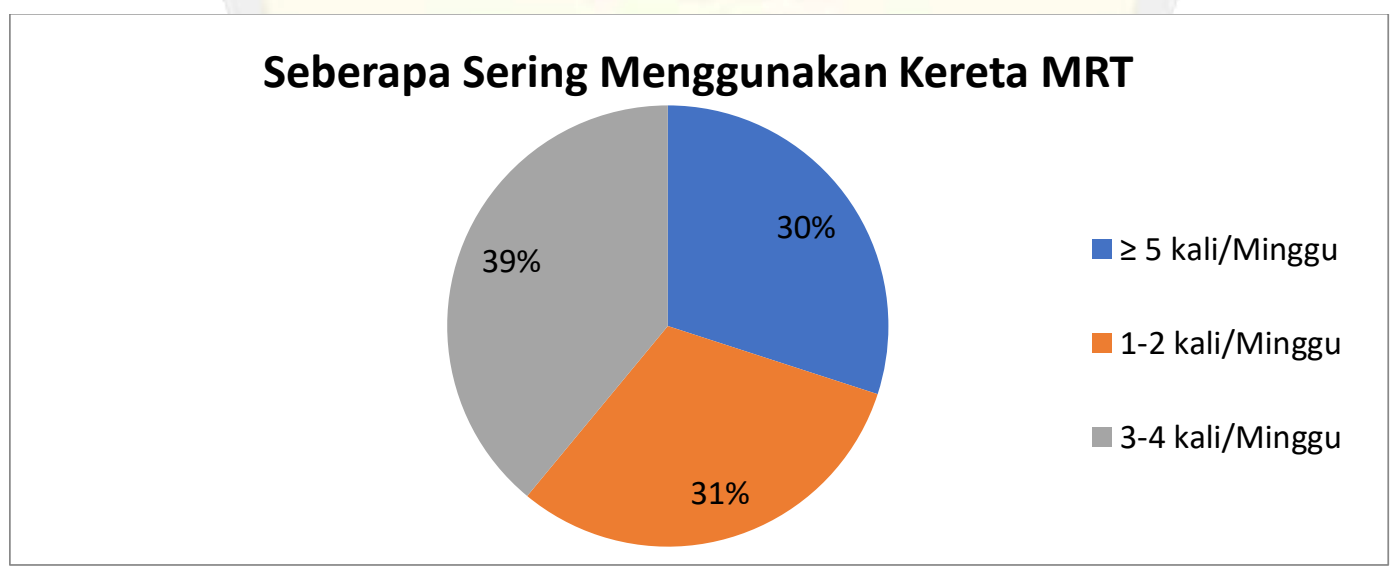

Gambar 4. Diagram Frekuensi Responden Berdasarkan Seberapa Sering Menggunakan Kereta MRT Jakarta

Sumber : Diolah dari data primer 


\section{IV.5. Analisis Regresi Linear Berganda}

Dari hasil pengolahan data dengan bantuan SPSS, terbentuk persamaan model regresi yang dapat dilihat dari output Tabel 2. Coefficients berikut:

Tabel 2. Coefficients

\begin{tabular}{|c|c|c|c|c|c|}
\hline \multirow[t]{2}{*}{ Model } & \multicolumn{2}{|c|}{ Unstandardized Coefficients } & \multirow{2}{*}{$\frac{\text { Standardized Coefficients }}{\text { Beta }}$} & \multirow[t]{2}{*}{$\mathrm{t}$} & \multirow[t]{2}{*}{ Sig. } \\
\hline & $\mathrm{B}$ & Std. Error & & & \\
\hline (Constant) & .457 & 1.144 & & .399 & .691 \\
\hline Fasilitas & .134 & .014 & .77 & 9.733 & .000 \\
\hline $\begin{array}{l}\text { Kualitas } \\
\text { Layanan }\end{array}$ & .172 & .079 & .17 & 2.182 & .032 \\
\hline
\end{tabular}

Dari hasil tersebut apabila ditulis dalam bentuk unstandardized, maka persamaan regresinya adalah sebagai berikut:

$$
Y=0,457+0,134 X_{1}+0,172 X_{2}
$$

Dimana Keputusan Pembelian $(\mathrm{Y})$ merupakan fungsi dari:

$$
\begin{aligned}
& 0,457=\text { Konstanta } \\
& X 1=\text { Fasilitas } \\
& X 2=\text { Kualitas Pelayanan }
\end{aligned}
$$

\section{IV.6. Pengujian Hipotesis Secara Parsial}

Pertama, untuk mengetahui apakah variabel Fasilitas (X1) berpengaruh signifikan terhadap variabel Keputusan Penggunaan Jasa (Y). Dengan membandingkan nilai t-hitung dan nilai t-tabel maka dapat disimpulkan bahwa Ho ditolak dan $\mathrm{H} 1$ diterima, karena nilai t-hitung (9.733) $>$ nilai t-tabel (1.985) dengan nilai sig. $>0,05$, sehingga secara parsial variabel Fasilitas berpengaruh secara signifikan terhadap keputusan pelanggan dalam menggunakan jasa transportasi MRT Jakarta.

Kedua, untuk mengetahui apakah variabel Kualitas Pelayanan (X2) berpengaruh signifikan terhadap variabel keputusan pengguna jasa $(Y)$. Dengan membandingkan nilai t-hitung dan nilai t-tabel maka dapat disimpulkan bahwa Ho ditolak dan $\mathrm{H} 1$ diterima, karena nilai t-hitung (2.182) 
$>$ nilai t-tabel (1.985) dengan nilai sig. $>0,05$, sehingga secara parsial variabel Kualitas Pelayanan berpengaruh secara signifikan terhadap keputusan pelanggan dalam menggunakan jasa transportasi MRT Jakarta.

\section{IV.7. Pengujian Hipotesis Secara Simultan}

Setelah dilakukan pengujian secara parsial, maka selanjutnya variabel independen akan diuji secara simultan terhadap variabel dependen dengan uji F. Uji F adalah uji signifikansi untuk menguji apakah persamaan regresi yang terbentuk valid atau tidak untuk digunakan sebagai alat memprediksi nilai dari variabel dependen. Pengambilan keputusannya adalah bila nilai sig. > 0,05, maka Ho diterima dan sebaliknya. Hasil perhitungan parameter model regresi secara bersama-sama diperoleh seperti terlihat pada Tabel 3 berikut ini:

Tabel 3. Anova

\begin{tabular}{|l|r|r|r|r|c|}
\hline Model & Sum of Squares & Df & Mean Square & F & Sig. \\
\hline Regression & 631.375 & 2 & 315.687 & 306.415 & $.000^{\mathrm{b}}$ \\
1 Residual & 99.935 & 97 & 1.030 & & \\
\multicolumn{1}{l|}{ Total } & 731.310 & 99 & & & \\
\hline
\end{tabular}

Sumber: Data diolah 2020

Dari Tabel di atas, terlihat bahwa nilai sig. $F$ adalah sebesar 0,000 . Karena nilai probabilitas atau sig. jauh lebih kecil dari 0,05, maka Ho ditolak. Hal ini berarti bahwa model regresi dapat digunakan untuk memprediksi Keputusan Pembelian. Dengan demikian diperoleh bahwa hipotesis yang menyatakan bahwa Fasilitas (X1) dan Kualitas Pelayanan (X2), secara bersama-sama memiliki pengaruh signifikan terhadap keputusan pelanggan dalam menggunakan jasa transportasi MRT Jakarta.

\section{IV.8. Koefisien Determinasi}

Koefisien determinasi $\left(R^{2}\right)$ pada intinya mengukur seberapa jauh kemampuan model dalam menerangkan variasi variabel dependen. Nilai koefisien determinasi adalah antara nol dan satu. Nilai $R^{2}$ yang kecil berarti 
kemampuan variabel-variabel independen dalam menjelaskan variasi variabel dependen terbatas, sedangkan nilai $R^{2}$ yang mendekati satu berarti variabel-variabel independen memberikan hampir semua informasi yang dibutuhkan untuk memprediksi variasi variabel dependen. Nilai koefisien determinasi dapat dilihat pada tabel 4 di bawah ini:

Tabel 4. Koefisien Determinasi

\begin{tabular}{|l|c|r|r|r|}
\hline Model & R & R Square & Adjusted R Square & Std. Error of the Estimate \\
\hline 1 & $.929^{\mathrm{a}}$ & .863 & .861 & 1.015 \\
\hline \multicolumn{5}{|c}{ Sumber: Data diolah 2020 }
\end{tabular}

Dari Tabel di atas dapat diketahui bahwa nilai koefisien korelasi $(R)$ sebesar 0,929, yang berarti terdapat hubungan yang sangat kuat antara variabel fasilitas dan kualitas pelayanan dengan variabel keputusan pelanggan pengguna jasa. Sedangkan koefisien determinasi $R$ Square $\left(\mathrm{R}^{2}\right)$ adalah sebesar 0,863 . Hal ini berarti $86,3 \%$ variasi kinerja anggota dapat dijelaskan oleh variasi dari kedua variabel independen yaitu fasilitas dan kualitas pelayanan.

Untuk mengevaluasi model regresi terbaik, digunakan Adjusted $R$ Square. Dari tampilan Model Summary besarnya Adjusted $R$ Square adalah 0,861 , hal ini berarti $86,1 \%$ variasi keputusan pelanggan pengguna jasa dapat dijelaskan oleh variasi dari kedua variabel independen yaitu fasilitas dan kualitas pelayanan. Sedangkan sisanya sebesar 13,9\% dijelaskan oleh sebab-sebab lain di luar model.

\section{PEMBAHASAN}

1. Berdasarkan hasil uji-t, Fasilitas secara parsial berpengaruh terhadap keputusan penggunaan jasa transportasi kereta MRT Jakarta, namun demikian dari 23 indikator yang mempengaruhi ada beberapa diantaranya perlu mendapatkan perhatian, karena berdasarkan perhitungan nilai indeks memiliki nilai terkecil, yaitu kursi penumpang, bangku prioritas dan bagasi barang sama memiliki nilai 83,71. Bisa 
dipahami kenapa ketiga hal tersebut mendapatkan penilaian paling kecil. Pertama kursi kereta MRT terbuat dari plastik. Kedua, bangku prioritas ada yang tergabung dengan bangku penumpang umum. Ketiga, jumlah bagasi barang cukup sedikit. Hal ini jauh tertinggal jika dibandingkan dengan $\mathrm{KRL}$ yang notabene adalah angkutan lama. Bangku KRL sudah dibalut dengan busa yang empuk, bagasi barang di sepanjang kursi penumpang dan bangku prioritas terpisah dengan bangku umum.

2. Berdasarkan hasil uji-t, Kualitas Pelayanan secara parsial berpengaruh terhadap keputusan penggunaan jasa transportasi kereta MRT Jakarta, namun ada dua indikator yang mendapatkan nilai indeks terendah dari pelanggan yaitu cepat tanggap dalam kesediaan merespon kebutuhan konsumen dan memprioritaskan penyandang disabilitas, lansia dan ibu hamil, yaitu sebesar 85,71 . Hal ini dapat dipahami, bahwa perusahaan-perusahaan jasa saat ini berusaha mengurangi pelayanan yang bersifat langsung/kontak langsung antara pelanggan dengan karyawan. Dengan kecanggihan model pelayanan saat ini, pelanggan dituntut untuk memahami sendiri berbagai proses pelayanan yang diberikan dengan berbagai model informasi yang telah disediakan, sehingga wajar jika daya tanggap dan empaty karyawan mendapatkan penilaian yang paling kecil oleh pelanggan kereta MRT.

\section{PENUTUP}

\section{Vl.1 Kesimpulan}

Hasil analisis dan pembahasan dapat disimpulkan sebagai berikut:

1. Berdasar hasil uji t dapat dijelaskan bahwa secara parsial variabel Fasilitas berpengaruh terhadap keputusan penggunaan jasa transportasi MRT Jakarta. Hal ini dibuktikan dengan besarnya nilai thitung Fasilitas sebesar $=9.733$ lebih besar dari t-tabel, yaitu 1,985. 
2. Berdasar hasil uji t dapat dijelaskan bahwa secara parsial variabel Kualitas Pelayanan berpengaruh terhadap keputusan pengguna jasa transportasi MRT Jakarta. Hal ini dibuktikan dengan besarnya nilai thitung Fasilitas sebesar = 2.182 lebih besar dari t-tabel, yaitu 1,985.

3. Berdasarkan hasil uji F dapat dijelaskan bahwa variabel - variabel bebas (Variabel independen) yang terdiri dari : Fasilitas dan Kualitas Pelayanan secara simultan mempunyai pengaruh terhadap keputusan pengguna jasa yaitu transportasi MRT Jakarta. Hal ini dibuktikan dengan besaran nilai $F$ hitung: 306,42 lebih besar dari $F$ tabel: 3.09 .

\section{IV.2. Saran}

Berdasarkan kesimpulan yang telah dikemukakan, maka peneliti memberikan beberapa saran yang diharapkan dapat meningkatkan keputusan pengguna jasa kereta MRT (Mass Rapid Transit) di Provinsi DKI Jakarta:

1. Untuk meningkatkan keputusan pelanggan dalam menggunakan jasa kereta MRT Jakarta, maka PT MRT Jakarta harus mampu menjaga fasilitas yang sudah ada. PT MRT juga harus meningkatkan kemanfaatan fasilitas yang memudahkan konsumen dalam menggunakan jasa transportasi tersebut seperti memperbaiki kursi penumpang, menambah bangku prioritas dan menambah bagasi barang.

2. Untuk meningkatkan kualitas pelayanan, sebaiknya perusahaan jasa transportasi kereta MRT (Mass Rapid Transit) Jakarta harus meningkatkan kemampuan daya tanggap karyawan dalam melayani/membantu pelanggan, serta memberikan perhatian lebih kepada penumpang yang membutuhkan khususnya penumpang prioritas.

3. Perbaikan fasilitas dan peningkatan kualitas pelayanan jasa transportasi kereta MRT (Mass Rapid Transit) Jakarta harus dilakukan 
secara terus menerus sesuai dengan kebutuhan pelanggan, sehingga pelanggan merasa bahwa menggunakan transportasi kereta MRT merupakan pilihan yang menyenangkan.

\section{DAFTAR PUSTAKA}

\section{BUKU}

Alma, Buchari. 2013. Manajemen Pemasaran dan Pemasaran Jasa Bandung: Alfabeta.

Andriansyah. 2015. Manajemen Transportasi Dalam Kajian Dan Teori. Cetakan Pertama. Jakarta: Fakultas IImu Sosial dan IImu Politik Universitas Prof. Dr. Moestopo Beragama

Ferdinand, Augusty. 2014. Metode Penelitian Manajemen. Semarang: BP Universitas Diponegoro.

Ghozali, Imam. 2016. Aplikasi Analisis Multivariate dengan Program IBM SPSS 23. Semarang: Badan Penerbit Universitas Diponegoro.

Kotler, Philip and Armstrong, Gary. 2012. Prinsip - Prinsip Pemasaran. Edisi 13. Jilid 1. Jakarta: Erlangga.

Kotler, Philip \& Armstrong, Gerry. 2014. Principle Of Marketing. New Jersey. Jakarta : Pearson Pretice Hall.

Sugiyono. 2017. Metode Penelitian Kuantitatif, Kualitatif, dan R\&D. Bandung : Alfabeta, CV.

Sutisna dan Pawitra. 2001. Perilaku Konsumen dan Komunikasi Pemasar. Bandung: Remaja Rosdakarya

Tjiptono , Fandy. 2014. Pemasaran Jasa. Yogyakarsa: Andi JURNAL

Desembrianita, Eva. 2016. "PENGARUH KUALITAS PELAYANAN, FASILITAS DAN HARGA TERHADAP KEPUTUSAN PELANGGAN UNTUK MENGGUNAKAN JASA HOTEL OVAL SURABAYA." Jurnal Riset Ekonomi dan Manajemen 16 (2) :345-354

Lempoy, Mandey and Loindong. 2015. "PENGARUH HARGA, LOKASI, DAN FASILITAS TERHADAP KEPUTUSAN MENGGUNAKAN JASA TAMAN WISATA TOAR LUMIMUUT (TAMAN EMAN) SONDER INFLUENCES." Jurnal EMBA 3 (1): 1072-1083.

Permatasari dan Hadi. 2017. "PENGARUH KUALITAS PELAYANAN, 
FASILITAS, DAN LOKASI TERHADAP KEPUTUSAN MENGGUNAKAN JASA DI PUSKESMAS TUREN-MALANG" Jurnal Aplikasi Bisnis 3 (2407-3741): 257-262

Trisnowati, Dalila Komala and Hari Susanta Nugraha. 2016. "PENGARUH HARGA DAN KUALITAS PELAYANAN TERHADAP KEPUTUSAN PENGGUNAAN JASA BENGKEL PT . ASTRA INTERNATIONAL TBK-DAIHATSU." Journal of Social and Politic of Science:1-8. 